\title{
Historia pública: ¿Una fatalidad historiográfica? - El público, lo público y la historia que publico: Conversación con Manuel Lucena Giraldo
}

Public History: Some considerations about this tragical topic in historiography. A dialogue with the historian Manuel Lucena Giraldo

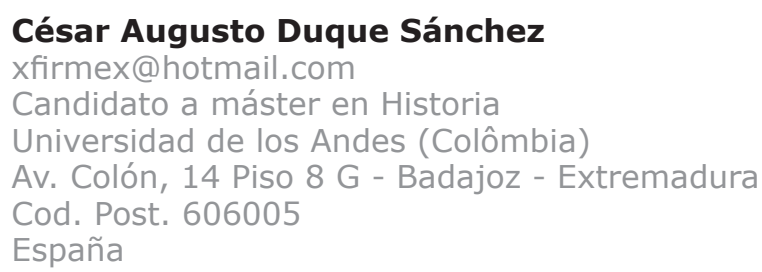

Palabras-clave

Campo historiográfico; Cultura historiográfica; Escritura de la Historia.

\section{Keywords}

Historiography Field; Historiographical culture; History writing. 
Publicar es como soltar papeles desde lo alto de una ventana: algunos son leídos, pero los demás ensucian las calles y se convierten en basura. Publicar es como lanzar mensajes en botellas al mar: es incierto que lleguen, aunque también es cierto que hay milagros.

Gabriel Zaid, Los demasiados libros, p. 76.

Los lectores no estarán contentos...Es culpa mía; tendría que haberlo interrogado mejor. Su pensamiento, como he expuesto, puede encontrarse en sus libros. El papel de un entrevistador es el de forzar la intimidad; es el de llevarlo a hablar sobre aquello que no hablaría por él mismo.

André Gide, Interviews imaginaires. París: Haut-Pays, Yverdon et Lausanne, 1943, p. 31.

El lunes 22 de septiembre de 2014 Manuel Lucena Giraldo y el autor de esta entrevista se reunieron en la oficina personal del historiador español para hablar, entre otros temas, de su experiencia personal, dado que Lucena es profesor, ensayista, editorialista y asesor, todo al mismo tiempo.

Para el momento de la entrevista, el profesor Lucena dictaba un curso electivo de Historia Global en la Universidad de los Andes de Bogotá, Colombia, curso que ha ofrecido en otras universidades del mundo.

Llaman la atención de su perfil las columnas de opinión que escribe sobre temas históricos, sus viajes por el mundo para conocer los avances del grupo de identidades del proyecto Barroco Hispano, al igual que los estrechos vínculos que mantiene con la historia de las emociones.

Esta entrevista, en particular, ofrece algunas reflexiones sobre el oficio de un historiador a inicios del siglo XXI. Las reflexiones generales han sido enfocadas al interés del historiador por abrir su disciplina a la esfera pública. Esto exige que expongan nociones que esta conversación pone sobre la palestra y son de gran relevancia para quienes se dedican al oficio de la historia en otros contextos. Se trata de nociones como lo público, lo común, lo popular, lo culto o lo vulgar, entre otras palabras que integran el sistema de referencias habituales entre personas dedicadas de la historia y que flotan permanentemente afuera y adentro del campo de la disciplina histórica.

Su título "Historia púbica: una fatalidad historiográfica", alude a ese destino recurrente que deben enfrentar todas las "generaciones" dedicadas al oficio moderno de la historia: ¿cómo hacer que la historia disciplinar se convierta en un componente del utillaje mental de la sociedad en la cual se escribe?

De esa manera, el debate empezaría con la formulación de algunas dudas: ¿plantear preguntas sobre la "historia pública" es hablar de un tema inevitable para quienes se dedican a los oficios de la disciplina histórica?, ¿al hablar de las circunstancias que la historia debe necesariamente enfrentar en su ejercicio hablamos de "fatalidades historiográficas"? 
Aunque parezca una pregunta obvia, ¿acaso hay un producto elaborado por la comunidad histórica que no suscite interés o que no parta de una inquietud pública?, ¿la escritura de la historia adquiere un valor adicional cuando se refiere a un tema público?, ¿las personas dedicadas a los oficios de la disciplina histórica deben ejercer la función de controlar las principales ideas de la historia que circulan por fuera de la esfera académica?

Parece que la simple formulación de estas preguntas oculta argumentos prácticos y valorativos de alto peso para el oficio. Es sólo el momento de formularlas, no de resolverlas. No obstante, lo aquí conversado mostrará indirectamente en la experiencia del profesor Lucena lo relativo a algunas de esas preguntas.

\section{Escritura de la Historia: Los formatos}

1. César Augusto Duque Sánchez: En sus clases se le oye hablar con entusiasmo sobre el libro de Anthony Grafton Los orígenes trágicos de la erudición. (GRAFTON, 1998) Es frecuente que esos comentarios manifiesten simpatía, en parte, con la crítica de Grafton al fetiche de la comprobación y el uso excesivo de la nota al pie en la academia.

Me arriesgo a decir que sus clases son una apuesta personal en la que se le propone al estudiante el encuentro con otros formatos, entre ellos el ensayo en su forma clásica.

En su opinión, ¿qué puede aportarle el ensayo a la disciplina histórica y a las ciencias sociales en general?

Manuel Lucena Giraldo: Lo que quisiera proponer aquí es el reencuentro con el archivo cultural y con los viejos formatos. Lo que sabemos es que, como historiadores hemos sobrevivido más de dos mil años, a partir de una mentalidad flexible, una capacidad de escritura y de narrativa, el manejo de diferentes géneros y, entre ellos, el ensayo para una época complicada como la que nos ha tocado vivir -que a mí me recuerda la época de Montaigne, de las "guerras de religión" en Francia-. El ensayo nos permite recuperar campo, recuperar lectores y ser pertinentes. A mí me parece que el reencuentro con una tradición clásica de humanidades que tiene muchísimo que decir y que está en el taller de todo historiador es importante.

En ese sentido, la propuesta de pensar en ensayos - con una poética clásica, cuidado, no es ensayo cualquier cosa -. El ensayo implica una posición de observación, una posición de coraje individual, un cuidado del idioma, una voluntad empírica nada "adjetivadora". Yo creo que a partir de ensayos que sean ensayos, los historiadores podemos contar muchas cosas importantes.

2. CADS: Su producción escrita es un ejemplo claro de esa búsqueda por explorar diferentes formatos. Observo que la escritura de artículos académicos no le ha impedido dedicar su tiempo a una columna para el diario ABC de España y la publicación de libros que tienen amplia circulación. En su carrera parecería haber un interés en comunicar ampliamente el "oficio de la historia". 
¿Qué ha ganado y qué ha perdido la escritura de Manuel Lucena Giraldo como intelectual al explorar estos formatos?

MLG: Yo creo que debemos manejar diferentes registros de escritura porque hay diferentes públicos. No es lo mismo escribir, en mi caso, en el suplemento cultural de un periódico - que son más de doscientos mil ejemplares todos los sábados, pongo por caso - que una monografía o un ensayo para la Revista de Occidente o evidentemente un libro de investigación pura.

Es preciso pensar para lo que sirve un historiador ahí, al público, a los lectores, a quienes no se compran un café sino que se compran un periódico algo que yo respeto profundamente pues hay un pacto, hay un contrato detrás de eso.

En ese sentido yo diría que lo que he ganado es versatilidad y flexibilidad. La escritura o las ganas de llegar a esos públicos de la historia, creo que me han hecho muy versátil. Quiero pensar que el contacto fantástico y venenoso al mismo tiempo con el periódico - y sus prisas y su inmediatez - me han mejorado como escritor, creo que me ha hecho escritor francamente.

$Y$ en cuanto a lo que he perdido, bueno, yo diría que he perdido tranquilidad. Hay algunos nichos académicos en los que eres rechazado si haces divulgación. Yo he escuchado decir a un "prohombre" aquello de "divulgación viene de vulgar" o - yo he escrito varias biografías, ¿no? -: "escribe biografías el que no sabe hacer otra cosa".

194 O sea, hay una academia "Torre de Marfil" y estar en un periódico te hace alejar un poco de ella. Bueno, ahí - en la Torre de Marfil - hay, digamos, buenas cosas también, no voy a negarlo: seguridad. Simplemente mi vida no ha ido por ahí.

Yo estoy muy contento de formar parte de una generación historiadores españoles que todos nos hemos formado fuera y que, más o menos, todos de un modo u otro, tenemos esa versatilidad, esa flexibilidad.

\section{Sobre la historia pública: Enseñanza y difusión de la historia}

3. CADS: Es igualmente interesante su desempeño profesional en asuntos educativos, miembro de comités científicos e investigador. Aunque no se desligan de su producción escrita, ahora quisiera que profundizáramos en estos oficios.

Recuerdo que en una entrevista que dio con su maestro John Elliot para el diario $A B C$ de España, usted señaló:

"Me indigna de manera particular es la falta de consideración por la Educación y de respeto y apoyo a los profesores".

¿Qué opina sobre este tema, como educador?

MLG: Un país que se respete tiene que respetar a sus educadores. Desgraciadamente yo creo que aquí - se refiere a Colombia - en los últimos treinta años, tienen grandes éxitos educativos en general y en la enseñanza de la historia en particular hay algo sustancial: el trabajo de grupo, el trabajo 
de equipo, pero también la comprensión de que el proceso de formación, de aprendizaje, tiene que hacerse sobre un determinado nivel de jerarquías.

Yo creo que es muy grave que haya una minusvaloración del oficio del historiador en los medios de comunicación masivos. A mí me parece muy grave que la gente lea novela histórica - mejor o peor; muchas veces peor: ni es novela, ni es historia - y la gente piense que aprende historia ahí y yo creo que eso es básicamente nuestra culpa.

Yo creo que hubo un feísmo historiográfico - cuanto peor escribías mejor historiador eras - y, evidentemente, el señor que compra un libro de historia y no puede pasar de la primera página -porque se le cae al pie y le hace una herida de lo insoportable y lo cargado que es el libro- nos puede enseñar sobre algo que se rompe y se rompe, quizás, de manera definitiva.

Yo estoy formado en Gran Bretaña y ahí no se ha producido esa ruptura entre la narración y la historia, afortunadamente. Creo que tenemos un problema de públicos y en los últimos treinta años - dependiendo de las tradiciones académicas - ha habido novelistas, periodistas que sin la menor información historiográfica, sin conocer lo que es la escritura de la historia, pretenden decir que ellos escriben historias verdaderas. Repito, es culpa de nosotros como historiadores, en buena parte, que eso ocurra.

4. CADS: En el campo de la enseñanza cómo lo ve. Usted ha sido profesor de varias universidades como Harvard, Tufts University (Boston), El Colegio de México y la Javeriana (Bogotá). En algunos de esos lugares ha enseñado Historia Global que es un enfoque relativamente reciente en la historia de la historiografía.

¿Ha pensado en las oportunidades de traducir ese conocimiento en la enseñanza escolar?

MLG: Es una cuestión complicada, yo creo que nos faltan datos quizás para poderlo responder. En mi caso, desde luego, apenas puedo hacer un apunte. Yo creo que es muy difícil que las nuevas tendencias historiográficas puedan llegar a los textos de historia, a la pedagogía, a las cartillas escolares, si todavía en el mundo académico de la enseñanza de la historia no están bien establecidas.

La pedagogía nacional - que sigue estando ahí- va poco a poco actualizando sus contenidos, pero yo estoy convencido de que queda mucho por hacer. En un debate reciente que tuvimos, recordábamos que, por ejemplo en el caso español, España es una nación desde mucho antes de que aparecieran los nacionalismos - en el siglo XIX- y, sin embargo, bueno, pues la pedagogía, como es lógico, va a intentar formar ciudadanos de acuerdo con ese contexto de nacionalismo.

Yo creo que una parte de eso, por supuesto, es fundamental e imprescindible, pero hay otra parte que tiene que ver con la ciudadanía global pos-nacional y yo creo que la Historia Global es una excelente asignatura porque nos recuerda que todos formamos parte de un mismo viaje, con independencia de ese accidente que es el lugar en donde nacemos, y yo creo mucho en la capacidad formativa que tiene la Historia Global. 
Otras tendencias recientes como la Big History nos recuerdan que no somos bichos solos en esta tierra, sino que también hay chimpancés, hormigas, peces; que la naturaleza que es un reflejo humano de lo que hay ahí fuera, cuenta que somos también animales existentes en un entorno ecológico.

Yo creo que es muy importante que los estudiantes de niveles anteriores primaria o bachillerato- sepan estas cosas porque les van a dar una gran ventaja, les va a permitir entender el mundo en el que están. Allí hace falta actualizar.

Pero tenemos antes que consolidar las nuevas asignaturas, las nuevas disciplinas que encajan de manera que al ser muy trasversales, muy interconectadoras, muy de escribir, no tienen todo el apoyo que deberían en el mundo académico. Pero estoy convencido de que al mediano plazo estarán perfectamente aceptadas y a partir de ahí [deben], tendrán influencia en todos los niveles educativos.

5. CADS: Es miembro del comité editorial de la sección Historia Global de National Geographic. Cuéntenos un poco más sobre su experiencia en la revista - por ejemplo cómo llegó a formar parte de ella, cómo se trabaja allí, qué objetivos tiene el trabajo de la revista al convocar especialistas en Historia Global y qué funciones tienen esos especialistas.

MLG: Bueno, digamos que uno de mis grandes logros recientes es formar parte del Comité de National Geographic en Historia Global. Ellos decidieron hace unos 196 cuatro años poner en marcha un gran proyecto editorial -que es una historia global en treinta volúmenes, que se hizo en España, pero que también tiene ediciones en Francia, en Italia y que está en proceso de ponerse en marcha también en inglés, en Estados Unidos-. Yo creo que es una expresión muy importante de tres cosas. La primera, el vigor y la importancia de las comunidades de historiadores profesionales - yo creo que hay muy buenos historiadores en este momento.

Lo segundo, creo que esos historiadores escriben bien, creo que hemos recuperado la capacidad de escribir o, por lo menos, el mensaje está claro: sin buena escritura no hay historia -y eso ya quien lo discute está muy caduco-.

Y lo tercero, la historia puede otorgar escala, facilita la comprensión de grandes problemas, permite aventurar buena prospectiva -claro, un buen amigo me decía que no hay nada que discutir, el peor futurólogo es el historiador-. Pero en el sentido de articular buen análisis y prospectiva de lo que las culturas globales y locales quieren decir sí lo hacemos desde la Historia Global -y por supuesto, hacerlo en National Geographic es un gran privilegio.

\section{CADS: ¿Cuántas personas están trabajando en el Comité?}

MLG: El Comité lo formamos cinco personas. Hay egiptólogos, hay medievalistas, hay arqueólogos, en fin, especialistas en diferentes disciplinas y, por supuesto, hay grandísimos historiadores que forman parte del Comité: Roben Lane Fox, el catedrático de clásicas en Oxford, John Elliot, Felipe Fernández Armesto, en fin, gente de primerísimo nivel. Para mí es un honor formar parte del mismo grupo. 
7. CADS: ¿Qué objetivo tiene el trabajo de la revista al convocar especialistas en Historia Global y qué función tienen esos especialistas en el Comité?

MLG: Los especialistas apoyan la búsqueda de temas relevantes y de autores posibles, esto es lo que hace un comité. Ayudamos a que ese talante creativo, prospectivo y relevante de la historia en la revista - Historia National Geographic - sea real, y aportamos nuestra experiencia y nuestras redes sociales para buscar los mejores autores para los temas imprescindibles.

En este caso, un Comité Asesor. No somos editores, ni tenemos nada que ver con la edición propiamente de dicha, pero sí sabemos de qué habría que escribir, qué sería interesante transmitirle al público, dónde hay una inquietud que no ha sido desarrollada $y$, si hay un poquito de suerte, de fortuna, quién podría escribir de ello.

8. CADS: ¿Cuál es el horizonte principal de "una" Historia Global para la revista National Geographic?

MLG: Recomponer el campo historiográfico; recomponer la relevancia de la historia $y$, en ese sentido, ha sido una gratísima noticia según me informaron, de que este modesto intento encontró público; que la gente quiere leer historia, pero quiere leer historia bien editada, por autores relevantes, por una comunidad flexible.

Los autores de la revista son, por un lado, gente joven, espléndida, magníficamente formada y también gente consagrada. O sea, hay una mezcla de gente veterana, experimentada, magnífica, maestros, pero también la revista está abierta a las aportaciones de gente joven que está haciendo un buen trabajo. No se trata de reproducir jerarquías académicas, sino de ser relevantes, todos en este trabajo de historiadores.

9. CADS: ¿Has trabajado en otro proyecto divulgativo en el sentido más amplio de la palabra, además del de la National Geographic?

MLG: Bueno, yo escribo regularmente en un suplemento cultural y los libros de historia. Yo soy crítico cultural de historia y viajes. Hablábamos antes de los periódicos y la historia pública de la historia.

En un periódico uno nunca sabe lo que va a ocurrir. En el último año he tenido la fortuna de que me encargaran pequeñas columnas sobre Carlo Magno, la Primera Guerra Mundial, los viajeros de los imperios y cosas de historia de España del siglo XVIII.

En ese sentido, yo quiero pensar que la Historia Global prepara muy bien no solo a los estudiantes sino también a los profesores para esa flexibilidad. Te saca del nicho del campo de seguridad y te coloca en una perspectiva metodológica trasversal; aprendes de muchas cosas.

Eso ayuda a que uno aprenda a escribir sobre las cosas más insospechadas que son las que ahora mismo, en algún lugar, están demandando un 
conocimiento histórico agregado. Ayer, por ejemplo, en El Espectador, salió una columna de Armando Montenegro - economista, historiador, admirado por mí - y él habló de algo tan contemporáneo como el origen del reino de Escocia al Reino Unido en 1707, que es básicamente un desastre financiero que tiene que ver con la locura de El Dorado, la fundación de las colonias escocesas a finales del siglo XVII en Nueva Caledonia, la ruina de las élites escocesas de ese momento y cómo la petición escocesa de unión al Reino Unido en 1707 les permite resolver ese problema de la terrible crisis que les causó la falacia de El Dorado tal y como la veían. Por supuesto que la historia es relevante y tiene muchas cosas que decir.

10. CADS: Como hemos comentado atrás, además de enseñar la asignatura este semestre en una universidad colombiana, la has ofrecido en países de habla inglesa, ¿qué diferencias notas en la recepción de la Historia Global según el público con el que has tenido contacto?

MLG: Yo creo que cada clase es un grupo y como cada clase, cada grupo es distinto. He encontrado estudiantes, profesionales, brillantes, deseosos de aprender, deseosos de saber y lo que me gustaría compartir con ellos, sobre todo, es que la Historia Global está basada en que los excepcionalismos son ficcionales.

En el caso concreto del contexto colombiano yo creo que tenemos que hacer un trabajo concreto de recomposición de campo historiográfico, en el cual tenemos que aludir continuamente a las escalas grandes, las grandes escalas de tiempo y espacio, típicas de la Historia Global para, espero yo, explicar que no existe un "caso" colombiano en la historia, no existe un carácter determinado, y que esto que ocurre aquí y que vemos como un problema inmediato, indescifrable o con unas características particulares, realmente ni es particular, ni es indescifrable, ni es inmediato.

Ahí es donde yo creo -y no me cabe duda de ello- que el entusiasmo de los estudiantes nos permitirá avanzar hacia la dirección correcta de la normalización, que es una palabra muy de Historia Global.

Gracias a ella podemos decir: "No, mire, lo que está ocurre en este país, está pasando en cincuenta contextos similares y seguro que podemos aprender de las experiencias de otros".

En Historia Global siempre estamos comparando escalas y por lo tanto hay un buen caudal de experiencia que se puede poner en marcha.

Al hilo de esta cuestión yo creo que mi experiencia como profesor - ien muchos países yai ¿no? - es que nadie va a darte respetabilidad, nadie te la va a conceder si tú no te la tienes.

Entonces, se puede decir que los historiadores somos relevantes, que tenemos cosas qué decir; que las humanidades en general son relevantes, que las ciencias sociales son fundamentales, que la globalización no hay quién la gobierne, salvo a base de cultura, de humanidades y de ciencias sociales... Somos la herramienta para que la globalización produzca efectos beneficiosos, porque somos "técnicos a la complejidad". 
Yo creo que eso hay que decirlo, hay que creérselo, hay que mantenerlo y si hay alguien que no se ha enterado mucho, pues pobrecito. Pero tenemos que ser conscientes de que en este momento, en el año 2014, ese es el papel que desempeñamos.

Somos portadores de malas noticias para los simplistas -porque yo creo que la base de nuestro trabajo es indicar que el ser humano es insospechado-, que la historia, como dice mi maestro Elliot, es "el estudio de las opciones de libertad" y que nada es sencillo aunque lo parezca, lo cual no le va a gustar a determinadas corrientes de populismos o de gente muy establecida, muy auto-referencial.

Creo que ahí hay algún papel pero tenemos que recuperar la autoestima, de alguna manera y saber que lo que decimos cuenta y que es importante y relevante y hacerlo de tal modo que esos agentes que están allí poniendo en marcha unas estrategias de difusión del conocimiento histórico, que eso no es historia; que una novela no es historia, puede ser una excelente novela -pero no es historia-; que la historia es otra cosa.

\section{Sobre la historia académica y otras formas de hacer historia en la Universidad}

11. CADS: Usted pertenece a la Academia Colombiana de Historia, también colaboró en el Diccionario Biográfico de la Real Academia de la Historia. Estas dos actividades las ejerce al mismo tiempo que sigue una trayectoria cercana a la de historiadores de Oxford, universidad en la que se formó con John Lynch, John Elliott y otros grandes maestros que exploran la historia comparada y que, entre otras cosas, han tenido fuertes debates con el nacionalismo español - a pesar de que han sido "revisitados", por ejemplo, por el separatismo catalán - y no son lejanos a la realeza inglesa o española.

Al referirse al diccionario biográfico de la Real Academia de la Historia recuerdo que usted decía para el $A B C$ :

Son interpretaciones legendarias. Siempre hay una aspiración a un origen mítico. La labor fundacional de la Real Academia de la Historia tiene que ver con separar la Historia de los grandes cronicones y de las leyendas. Y en ese sentido, la Academia de la Historia cumple con este Diccionario uno de sus fines fundacionales (ASTORGA 2011, párrafo. 41).

¿Por qué cree que las historias académicas convencionales permanecen en algunos países - por ejemplo en España - después de la aparición de proyectos muy interesantes de historia crítica y de la llegada nuevos enfoques de la historiografía?

MLG: Daré una respuesta decepcionante e ilustrada. Yo creo que quienes critican más a las academias son los que no forman parte de ellas. Yo creo que la Academia designa una corporación y yo creo que es muy bueno que existan las academias de la historia, que son organismos que acumulan sabiduría, conocimiento, experiencia y densidad institucional. A mí me gustan las academias y, por supuesto, es un altísimo honor haber sido recibido como correspondiente extranjero en la Academia Colombiana de Historia. 
Sí es verdad que la demanda de historia y su concreción, su engranaje con la tradición académica es un reto para todas las academias y, seguramente, hay muchas cosas que se pueden hacer, pero yo creo que hacen un gran papel. En el caso español, el diccionario biográfico de historia era algo que no teníamos y que es una obra extraordinaria. Y al final los públicos de la historia son los que determinan lo que hay que decir, más allá de que se debata. El diccionario biográfico español es uno de los libros más consultados, si no el más consultado en la biblioteca nacional de España, por ejemplo.

Yo, a eso animaría, a quien haga una generalización a partir de lecturas apresuradas: que vaya al diccionario y que lo vea, que lo consulte y que vean lo que es y que ahí hay cientos y cientos de personas que hemos colaborado.

Que haya debates sobre determinadas biografías y sobre determinados campos, debería formar parte de la discusión colectiva en la cual la autoría es compartida. Pero la descalificación de la obra general, sin conocerla y, sobretodo, del enorme esfuerzo de cientos y cientos de personas no es mayor cosa.

\section{CADS: ¿Por qué y cómo hacer biografías en la "era de la Historia Global"?}

MLG: Porque el ser humano siempre tiene interés por las conexiones y por lo que le ocurre a su alrededor. La biografía siempre tiene público, porque los humanos somos curiosos y satisfacer esa curiosidad es una de las obligaciones de la historia. Así que yo creo que la biografía es un género espléndido,

200 muy de gran público, que te enseña mucho a escribir, a investigar. Es difícil no encontrar un gran historiador actual que no haya escrito biografías. Mi querido maestro John Elliot escribió a su manera la del Conde Duque de Olivares y escribió un ejercicio fantástico, es una biografía doble de Richelieu y Olivares, que para mí es una obra maestra. Así que, por supuesto, hay que escribir biografías.

\section{Proyectos}

13. CADS: ¿Qué proyectos intelectuales tiene en mente para el futuro?

MLG: Me gustaría en el largo plazo, estamos hablando de tres a cinco años, poner al día una historia del Imperio español. Yo creo que una Historia Global del Imperio español la necesitamos, posnacional, por supuesto, "posnacionalista". Creo que el primer Imperio Global de la historia moderna es el Imperio Hispano-Portugués de los "Felipes" -de Felipe II, III y IV (1680-1740)-; creo que ahí está la matriz de la globalización moderna y contemporánea y, bueno, hemos hecho un gran trabajo en los últimos treinta años y me encantaría tener tiempo y posibilidades de poder hacer ese manual, ese libro que articule los distintos enfoques. 


\section{Referencias bibliográficas}

ASTORGA, Antonio. Los jóvenes están hartos de los políticos de la vieja generación. El hispanista Sir John Elliott y el historiador Manuel Lucena opinan sobre el movimiento de los <indignados>. Diario ABC [Versión web]. Disponible en: http://www.abc.es/20110529/cultura/abci-hartospoliticos-201105290555.html. Entrevista: 30 mai. 2011.

GRAFTON, Anthony. Los orígenes trágicos de la erudición. México D.F: FCE, 1998.

GIDE, ANDRÉ. Interviews imaginaires. París: Haut-Pays; Yverdon et Lausanne, 1943.

LUCENA GIRALDO, Manuel. A los cuatro vientos: Las ciudades en la América Hispánica. Madrid: Marcial Pons; Fundación Carolina; Centro de Estudios Hispánicos e Iberoaméricanos, 2006.

- Naciones rebeldes. Las revoluciones de independencia latinoamericanas. Madrid: Taurus; Penguin Random House G. E, 2010.

- Francisco de Miranda: La aventura de la política. Caracas: Madrid: Edaf, 2011.

82 objetos que cuentan un país: Una historia de España. Madrid: Penguin Random House, 2015.

ZAID, GABRIEL. Los demasiados libros. Barcelona: Anagrama, 2006. 